AÇÃO MIDIÁTICA, n.17. Jan./Jun. 2019. Curitiba. PPGCOM-UFPR. ISSN 2238-0701

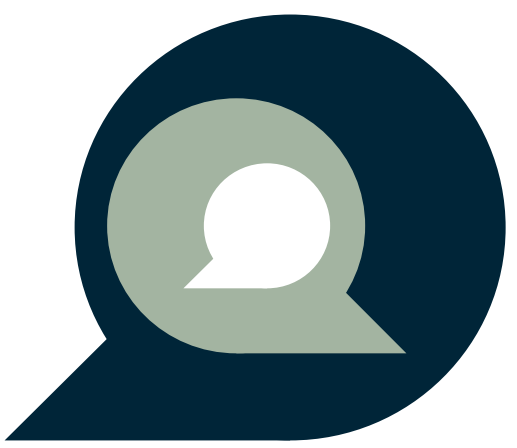




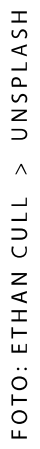

I)
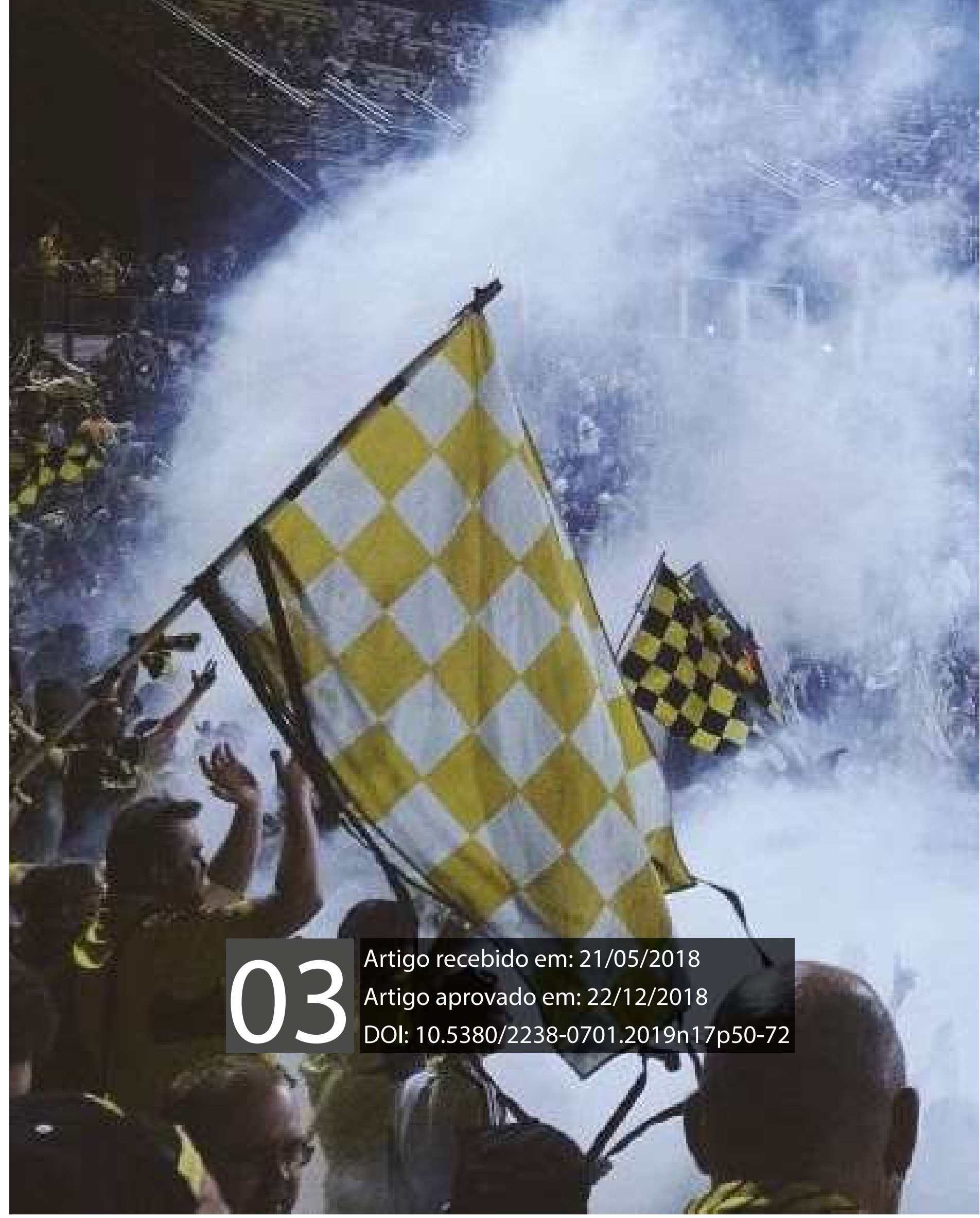
Redes Sociais e Futebol: as torcidas retratadas através do Instagram durante a final da Liga dos Campeões da Europa 2016 


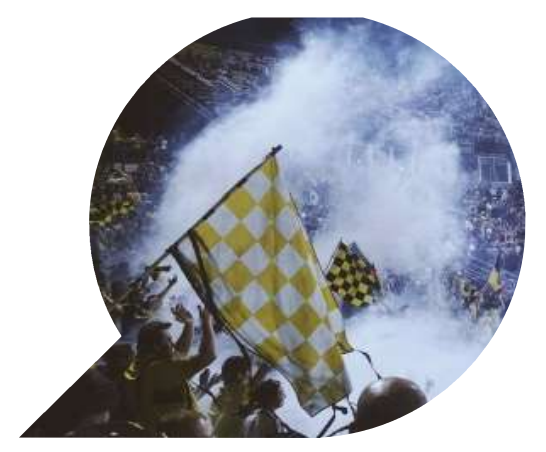

\section{Redes Sociais e Futebol: as torcidas re- tratadas através do Instagram durante a final da Liga dos Campeões da Europa 2016}

Social Networks and Football: the fans portrayed through Instagram

during the UEFA Champions League 2016 final

CARLOS ROBERTO GASPAR TEIXEIRA ${ }^{1}$

ROBERTO TIETZMANN ${ }^{2}$

Resumo: A partir da realização da final da Liga dos Campeões da Europa, em maio de 2016, buscou-se analisar o comportamento manifestado pelos usuários da rede social Instagram, tendo em vista como acontece a relação entre os espaços físicos e a forma como os torcedores das equipes finalistas se autorrepresentam. Foram coletadas fotos, segmentadas por geolocalização, do entorno dos estádios das equipes finalistas: Real e Atlético, ambas de Madrid (Espanha), assim como do estádio onde o jogo foi realizado: San Siro, na cidade de Milão (Itália). A análise considerou a forma como os torcedores se representavam, levando em conta o número de pessoas presentes nas imagens. Um dos resultados

1 Carlos Roberto Gaspar Teixeira é doutorando em Comunicação Social pela Escola de Comunicação, Artes e Design - Famecos. E-mail: eu@ocarlosteixeira.com.br.

2 Roberto Tietzmann é docente da PUCRS, pesquisador no PPGCOM e PPGL e coordenador do grupo de pesquisa ViDiCa - Cultura Digital Audiovisual. E-mail: rtietz@pucrs.br. 
constatado foi de que, apesar das localizações apresentarem ambientes coletivos e com grande concentração de pessoas (estádios de futebol), a maioria das fotos continha apenas uma ou nenhuma pessoa. Tal fenômeno indica que a mobilidade tecnológica, de algum modo, trouxe um movimento de individualidade. Também foram verificadas transgressões em relação à veracidade da presença física nos locais, já que os usuários marcavam uma localização que não necessariamente era a representada na postagem.

Palavras-chave: Instagram; futebol; torcida; autorrepresentação; Comunicação.

Abstract: After the final match of the Champions League of Europe in May 2016, the authors sought to analyze behaviors manifested by users on the social network Instagram, examining how the relationship between the physical spaces and the way the fans of the finalist teams self-represented. Photos and geo-targeted data were collected from the stadiums of the finalist teams: Real and Atlético, both from Madrid (Spain), as well as from the stadium where the game took place: San Siro in Milan. The analysis examined how the fans represented themselves, taking into account the number of people present in the images. One of the results was that, although the locations present collective environments with a large concentration of people (soccer stadiums), most of the photos contained only one or no person at all. Such phenomenon indicates that the technological mobility, in some way, produced a tendency of individuality. Transgressions were also verified regarding the veracity of the physical presence in the places since the users marked a location that was not necessarily represented in the posting.

Keywords: Instagram; Soccer; Fan; Self-representation; Communication.

\section{Introdução}

A Liga dos Campeões da Europa pode ser considerada um dos maiores eventos esportivos mundiais, com periodicidade anual, que reúne os principais times do futebol europeu. Conforme regulamento da UEFA (2015), os clubes são selecionados a partir da classificação em seus respectivos campeonatos nacionais e de um ranking baseado nos desempenhos das últimas cinco temporadas. A edição do campeonato, 
realizada entre os meses de setembro de 2015 e maio de 2016, teve a partida final ocorrida no dia 28 de maio de 2016 entre as equipes Real Madrid e Atlético de Madrid. O jogo foi disputado em um campo neutro no estádio Giuseppe Meazza (usualmente chamado de San Siro), em Milão, cidade ao norte da Itália, com capacidade para 80 mil pessoas ${ }^{2}$, tendo um público pagante de quase 72 mil pessoas $^{3}$. Curiosamente, a final disputada entre rivais da capital espanhola, foi realizada à aproximadamente 1,5 mil quilômetros de distância da cidade natal. Vale destacar que o estádio sede da final, sempre é escolhido pelo Comitê Executivo da UEFA um ano antes da realização da competição, podendo ou não coincidir com a sede de um, ou ambos finalistas.

O caráter continental do evento e as distâncias entre as equipes, suas cidades-sede e seus torcedores, bem como a participação de jogadores de alto nível de todo o mundo, colocam a Liga dos Campeões como um produto midiático de excelência. A UEFA, gestora do processo e proprietária da marca, tem tirado proveito dos meios de comunicação desde suas primeiras edições, atualmente explorando mais profundamente sua presença ativa nas redes sociais digitais ${ }^{4}$. Tais meios impulsionam um contexto onde as informações são publicadas e compartilhadas em uma circulação potencialmente global, ainda que com interesses segmentados, o que estimula a proliferação de nichos e comunidades específicas movidas pelo evento principal.

A segmentação por interesses e afinidades comentada por Negroponte (1995) e Levy (1995) é bem conhecida entre plateias de futebol. Os espectadores anteriormente mensurados apenas pelas estatísticas de público pagante, hoje podem ser observados, descritos e analisados a partir de suas atividades e comportamentos em sites de redes sociais. Segundo Recuero (2015), os públicos agora estão estruturados em redes, elaborando manifestações através dos mais variados tipos de publicações nesses sites que listam e relacionam suas interações. A autora elenca algumas das características presentes nestes registros: 1) as interações tendem a ficar inscritas na rede por tempo indeterminado; 2) a

2 SanSiro.net. Disponível em: http://www.sansiro.net/?page_id=1699\&lang=en. Acesso em: 18 jun. 2016

3 UEFA. Disponível em: http://www.uefa.com/newsfiles/ucl/2016/2015789_fr.pdf. Acesso em: 19 abr. 2017

4 Os perfis oficiais da UEFA são altamente ativos nas redes sociais: Facebook: https://www.facebook.com/uefachampionsleague, Twitter: https://twitter.com/uefacom?lang=pt, Instagram: https://www.instagram.com/uefachampionsleague. 
busca e recuperação de tais interações é tarefa simples; 3) elas são reproduzidas facilmente; 4) tem um alto potencial de alcance e multiplicação. Assim, ao recuperar esses registros é possível chegar a um entendimento a respeito dos públicos e suas interações com o evento e entre si.

Seria então possível estabelecer relações do que é comum entre os espaços físicos (estádios) e as formas de representação realizadas pelas comunidades envolvidas (torcedores de Real e Atlético de Madrid)? Este artigo tem como objetivo analisar o comportamento dos usuários, a relação entre os espaços físicos e a forma como os torcedores das equipes finalistas se representaram na rede social digital Instagram. Para isso, as fotos postadas nessa plataforma foram mapeadas por geolocalização a partir da segmentação dos estádios potencialmente envolvidos na partida final da Liga: Santiago Bernabéu (Real Madrid), Vicente Calderón (Atlético de Madrid) e San Siro (palco da grande final). O período analisado contemplou o final de semana em que o jogo foi realizado, entre os dias 27 (sexta-feira) e 30 (segunda-feira) de maio de 2016. A partir dessa coleta os autores buscaram um entendimento do comportamento da audiência digital dos torcedores em mobilidade, por meio do registro de suas atividades no ambiente digital do Instagram, apresentando os resultados através de visualizações de dados.

\section{Tecnologias de comunicação e mobilidade}

Eventos como a Liga dos Campeões da Europa interligam diversos níveis de tecnologias e redes de comunicação, desde os dispositivos móveis pessoais de cada torcedor até as coberturas e transmissões globais. Além disso, são inúmeros os conteúdos criados por agentes oficiais ou entusiastas, em um panorama multifacetado cujo ponto de atração e convergência em comum é o interesse pela competição esportiva e a sensação de estar participando de uma experiência coletiva. De acordo com Jenkins (2009, p. 29), a convergência pode ser definida como:

O fluxo de conteúdos através de múltiplas plataformas de mídia, à cooperação entre múltiplos mercados midiáticos e ao comportamento migratório dos públicos dos meios de comunicação, que vão a quase qualquer parte em busca das experiências de entretenimento que desejam.

A competição pode ser observada não apenas como uma demons- 
tração de lealdade dos torcedores a seus times preferidos, mas também um evento de entretenimento capaz de agregar transversalmente novos públicos e captar futuros consumidores. Ao tratar da convergência das mídias, Salaverría (2003) pondera a necessidade de levar em conta quatro dimensões articuladas entre si na sua formação, podendo ser aplicadas a este caso:

- Dimensão empresarial: nível mais geral, onde as empresas utilizam um processo de diversificação midiático.

- Dimensão tecnológica: a revolução dos instrumentos tecnológicos que possibilitam os processos de composição, produção e difusão dos meios.

- Dimensão profissional: os profissionais que se adaptam a essa nova realidade e utilizam as empresas e suas tecnologias na produção de conteúdos cada vez mais dinâmicos.

- Dimensão comunicativa: com a internet houve um desenvolvimento e avanço na integração de códigos comunicacionais e uma linguagem multimídia.

As dimensões apresentadas por Salaverría (2003) podem ser associadas a Liga dos Campeões da Europa. O número de empresas interessadas em patrocinar competições esportivas é cada vez maior, impactando também no crescente número e variedade de profissionais envolvidos que, juntamente com o desenvolvimento de novas tecnologias, integram e ampliam as formas de comunicação e divulgação deste evento esportivo. Logo, é viável considerar a Liga dos Campeões da Europa, e principalmente a sua final (pela maior relevância), um fator centralizador das dimensões apresentadas. É possível perceber assim uma tendência e adaptação da sociedade, empresas e meios de comunicação na utilização das novas tecnologias e mídias, assim como nas possibilidades de amplificação e transgressão da comunicação através dessas convergências. Essa expansão por diversos canais, atrelada aos avanços tecnológicos, proporcionou um processo de digitalização das informações. Negroponte (1995) aponta a transformação do DNA da informação de átomos em bits, o que antes era transmitido fisicamente por meio de "átomos" com uma distribuição limitada, hoje é digitalizado e comprimido em "bits", atingindo uma velocidade e capacidade de distribuição acentuada. Juntamente com essa digitalização da informa- 
ção, as evoluções tecnológicas e o baixo custo de produção de microprocessadores, de acordo com Rheingold (2003), possibilitaram a presença desses chips em todos os lugares e até mesmo nas coisas e nos objetos. Isso acabou criando uma rede invisível de intercomunicação entre todos os dispositivos que estiverem conectados e os sujeitos que os utilizam.

Essa capacidade comunicacional foi extremamente amplificada na sociedade através dos celulares, onde "com o surgimento dos aparelhos portáteis, textos, imagens e sons tornaram-se ubíquos, enquanto celulares vão ficando cada vez mais turbinados, circulando por todo o canto" (SANTAELLA, 2007, p. 133). À medida que as tecnologias móveis se desenvolveram, sua incorporação na rotina permitiu que pessoas, coisas e locais estivessem constantemente interligados em rede. Segundo dados da Pesquisa Nacional por Amostra de Domicílios (IBGE, 2015), o uso de telefone celular já aparece como o principal meio de acesso à internet no Brasil, 92,1\% dos domicílios brasileiros acessam à internet por meio do telefone celular, enquanto $70,1 \%$ dos domicílios o fizeram por meio do microcomputador. Titcomb (2016) ressalta que a utilização da internet no mundo já é maior em dispositivos móveis do que em computadores, entretanto, em alguns países como o Reino Unido, o número de acessos mobile ainda não superou o do computador.

Utilizando esses dispositivos, de acordo com Rheingold (2003), grupos de pessoas conquistaram novas formas de interagir e realizar trocas a qualquer momento e em qualquer lugar. Surge, assim, um novo formato social que tornou possível a combinação entre computação, comunicação, reputação e reconhecimento de local. Ao analisar esse processo, o autor utiliza o termo "Smart Mobs" para definir as pessoas que são capazes de agir em conjunto mesmo sem conhecer uns aos outros. Essas pessoas estabelecem relacionamentos e colaborações de uma maneira nunca antes possível, pois carregam aparelhos que possuem capacidades tecnológicas tanto de comunicação como de computação. Seus celulares os conectam com outros aparelhos de informações no ambiente, assim como com os celulares de outras pessoas (RHEINGOLD, 2003).

O rompimento das barreiras físicas dos espaços e a possibilidade de relacionamento e conexão de qualquer pessoa em qualquer lugar provocaram impactos na forma como as pessoas e a sociedade se relacionam. Isso ocorre dentro de um ambiente que não é mais físico e local, mas sim, virtual. O termo "ciberespaço" define esse local que, segun- 
do Santaella (2007, p. 178), "é o espaço informacional das conexões de computadores ao redor do globo, portanto, um espaço que representa o conceito de rede e no qual a geografia física não importa, pois qualquer lugar do mundo fica à um clique de distância”.

De acordo com Meyrowitz (1985), a espacialidade dos locais e do tempo transformou espaços privados em públicos, tornando-os acessíveis mundo afora. Isso impactou diretamente na identidade e na formação de grupos. Antigamente, a separação física auxiliava na criação de uma separação social, os indivíduos estavam juntos, porém, isolados no mesmo espaço ou em local similar: casa, escritório, lojas, bares, etc. Hoje, entretanto, pessoas podem interagir e ter experiências em conjunto independentemente de onde estão. O local físico agora cria apenas um único, porém especial, tipo de experiência de compartilhamento em grupo, enquanto no ciberespaço são criadas inúmeras novas formas de acesso e relacionamento que pouco tem a ver com a localização. A experiência compartilhada do momento também produz a percepção de um capital social que é circulada pelos participantes.

Turkle (2011) faz uma crítica direta a esses processos. Segundo a autora, todos esses fatores tecnológicos e sociais citados levam a sociedade a um comportamento que ela chama de "sozinhos juntos" (alone together). Esse comportamento é definido como os efeitos psicológicos que a internet e as tecnologias têm no modo de agir das pessoas, considerando que a vida online tende a promover relações e conexões cada vez mais superficiais e emocionalmente preguiçosas. A possibilidade de conexão constante entre as pessoas as aproxima virtualmente, porém, fisicamente elas ficam cada vez mais sozinhas. A relação entre espaço físico, virtual e pessoas, assim como seus comportamentos, é a crítica fundamental da autora.

Ao analisar os espaços físicos na era da mobilidade, Santaella (2007) enfatiza que lugares não podem ser separados de seu contexto de experiência. A autora ressalta que devido ao fato da pessoa estar sempre em movimento e conectada, ela está ao mesmo tempo presente e ausente em um mesmo espaço, "gerando a vivência da ubiquidade: estar lá, de onde me chamam, e estar aqui, onde sou chamado, ao mesmo tempo" (ibidem, p. 236). Já Meyrowitz (2003) salienta que a medida em que as pessoas confiam cada vez mais em computadores, telefones celulares, televisão e outras mídias eletrônicas para informação, consumo e inte- 
rações humanas, poucas de suas atividades e uma pequena parte de sua identidade fica atrelada ou moldada por locais específicos e regras fixas. A sociedade não armazena mais coisas em casa, e sim nos locais onde as encontram, com marcações na internet por exemplo, assim como os nômades deixavam rebanhos e frutas em seus habitats naturais para acessar quando precisassem. Seria essa a definição de Meyrowitz (2003) para os "nômades globais na savana digital".

Dessa forma, é possível analisar como se dá a relação entre a comunidade local e o espaço físico dentro de um ambiente digital. A partir dos registros realizados em diferentes locais pode ser possível analisar as formas de manifestação das pessoas que passaram por esses espaços. Os "nômades globais" registram e armazenam frequentemente suas informações em sites de redes sociais, desse modo pode ser viável encontrar pontos comuns entre os locais, publicações e quem as realizou.

Um dos ambientes onde todos esses fatores estão relacionados é o estádio de futebol. Nele existe uma grande concentração física de pessoas que, mesmo juntas, podem ainda ser analisadas individualmente através de seus registros na internet. Também é possível considerar que os indivíduos estão presentes ao mesmo tempo em vários lugares: fisicamente no estádio e virtualmente nas redes sociais. A final da Liga dos Campeões da Europa, entre duas equipes rivais da mesma cidade (Madrid) em outro país (Itália), pode ser considerada um cenário rico para a análise das relações entre o local físico e as comunidades dentro das redes sociais digitais. Esse artigo buscou estabelecer possíveis descobertas sobre a comunicação em mobilidade através de audiências em deslocamento e torcedores em localidades diferentes: os estádios de origem e o estádio da partida.

\section{Análise sobre a representação dos torcedores no Instagram na fi- nal da Liga dos Campeões da Europa}

No dia 28 de maio de 2016 (sábado) foi realizada a partida final da Liga dos Campeões da Europa entre dois rivais locais espanhóis, Real Madrid e Atlético de Madrid, em campo neutro à aproximadamente 1,5 mil quilômetros de distância da cidade de origem das equipes. Para analisar o comportamento dos espectadores e torcedores relacionados mais diretamente ao jogo foi estabelecido como período de coleta os dias entre 27 e 30 de maio, contemplando o final de semana do evento, 
assim como o primeiro dia útil após jogo. Esse intervalo de tempo foi considerado suficiente por englobar os principais dias de repercussão do acontecimento, além de buscar incluir possíveis deslocamentos de torcedores que tiveram a possibilidade ou interesse de comparecer fisicamente ao evento.

A plataforma de rede social digital escolhida para análise foi o Instagram, que, além de possuir um viés voltado prioritariamente para o compartilhamento de fotos, permite a geolocalização das postagens, sendo essa uma funcionalidade bastante utilizada por seus usuários que comumente marcam o local de suas fotos. Para a coleta de dados foi utilizado o software gratuito IFTTT ${ }^{5}$ (If This Than That). Esse sistema permite criar regras de registro de diferentes tipos de dados em diversas plataformas. Com isso, foi possível executar regras que salvassem todas as fotos publicadas no Instagram em cada uma das áreas determinadas. Foram criadas três receitas de coleta abrangendo o período selecionado e as áreas dos estádios que envolveram as equipes finalistas: a) Estádio Giuseppe Meazza (San Siro), local do jogo da final; b) Estádio Santiago Bernabéu, da equipe do Real Madrid; e c) Estádio Vicente Calderón, do time do Atlético de Madrid.

Após a coleta foi realizada uma filtragem manual de todas as fotos, retirando aquelas imagens que não foram produzidas por torcedores, como imagens publicitárias, reproduções jornalísticas, fotos de jogadores, criações publicitárias, "memes de internet", etc. Essa filtragem foi necessária tendo em vista que o objetivo central da pesquisa era analisar como ocorria a representação pessoal dos torcedores. A base final da coleta totalizou 1.826 imagens, divididas entre as três diferentes localizações e os quatro dias ${ }^{6}$. A seguir são apresentados os principais resultados obtidos através das visualizações dos dados.

Sintetizando vários autores como Yuexiao (1988) e Young (1987), cabe afirmar que um dado colocado voluntariamente online passa a ser entendido como informação quando responde a uma questão formulada. É seguro afirmar, portanto, que praticamente qualquer elemento da natureza ou produzido pelo homem pode ser potencialmente informa5 IFTTT. Disponível em: https://ifttt.com. Acesso em: 30 mai. 2016. Vale ressaltar que, até o dia 31 de maio de 2016, as coletas no Instagram dentro da plataforma IFTTT permitiam a coleta e o armazenamento das fotos dos usuários. A partir do dia 31 de maio, conforme divulgado em seu blog oficial (Disponível em: <https://ifttt.com/blog/2016/05/a-change-in-how-instagram-works-with-ifttt>. Acesso em: 19 abr. 2017) não foi mais possível realizar esse tipo de coleta.

6 Todos os dados e imagens de coletas estão disponíveis em: <http://www.coletachampions2016. tk>. Acesso em: 19 abr. 2017. 
tivo. O diferencial é a presença de uma chave de interpretação que acontece através de uma série de questionamentos iterativos do observador, o que pode ser facilitado por uma forma visual.

De acordo com Heer, Bostock e Ogievetsky (2010), a utilização das visualizações gráficas de dados colabora com a compreensão de padrões presentes em grandes quantidades de dados, simplificando o reconhecimento de tendências principais e registros desviantes. Isso serve como um subsídio para a criação de explicações visuais na forma de gráficos, conceituados a partir das definições de autores como Sancho (2001) e Cairo (2013) como a representação em imagem e texto de um conjunto de dados organizado com o propósito de informar com mais clareza e agilidade.

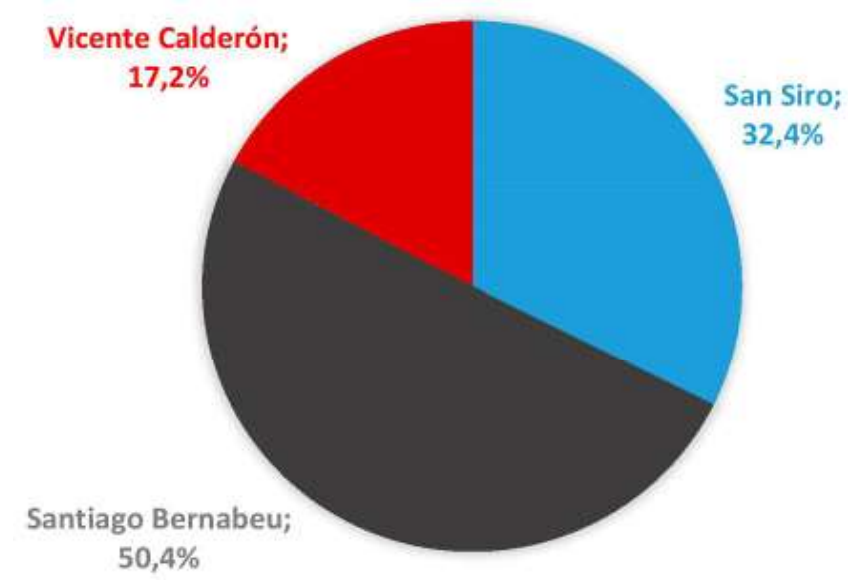

Gráfico 1 - Imagens por estádio

Fonte: Elaborado pelos Autores/ Mosaicos das fotos coletadas disponíveis em: http://www. coletachampions2016.tk.

Ao verificar a divisão da quantidade de fotos por localidade, o estádio do Real Madrid (Santiago Bernabéu) apresentou praticamente a metade do total dos registros, seguido pelo estádio onde foi realizado o jogo final (San Siro) e por último o estádio do Atlético de Madrid (Vicente Calderón). Foi possível observar que o estádio de realização da partida final não foi o lugar com mais fotos postadas, apesar de ser onde toda a atenção estava direcionada. As imediações do estádio do Real Madrid foram mais ativas do que o local da partida em si. Uma das possíveis explicações para tal fato seria que o Real Madrid, de acordo com pesquisa divulgada pelo Centro de Investigaciones Sociológicas, em junho de 2014, é considerado a equipe com a maior torcida da Espanha, com 37,9\% dos torcedores espanhóis (cerca de 18.000.000). Já o Atlético ocupa a tercei- 
ra posição de maior torcida com 6,1\% (cerca de 2.900.000), ficando atrás do Barcelona ${ }^{7}$. Ao considerar que o Real tem 6 vezes mais torcedores que o Atlético, é possível inferir que também possui até 6 vezes mais probabilidade de publicações por parte de seus torcedores. Outro fato a ser considerado foi o evento oferecido pelo Real Madrid no seu estádio, no qual foram disponibilizados telões para acompanhar a partida final realizada na Itália, algo que aconteceu conforme ilustra a figura 1 com o ingresso do evento da retransmissão da final postado por um torcedor.

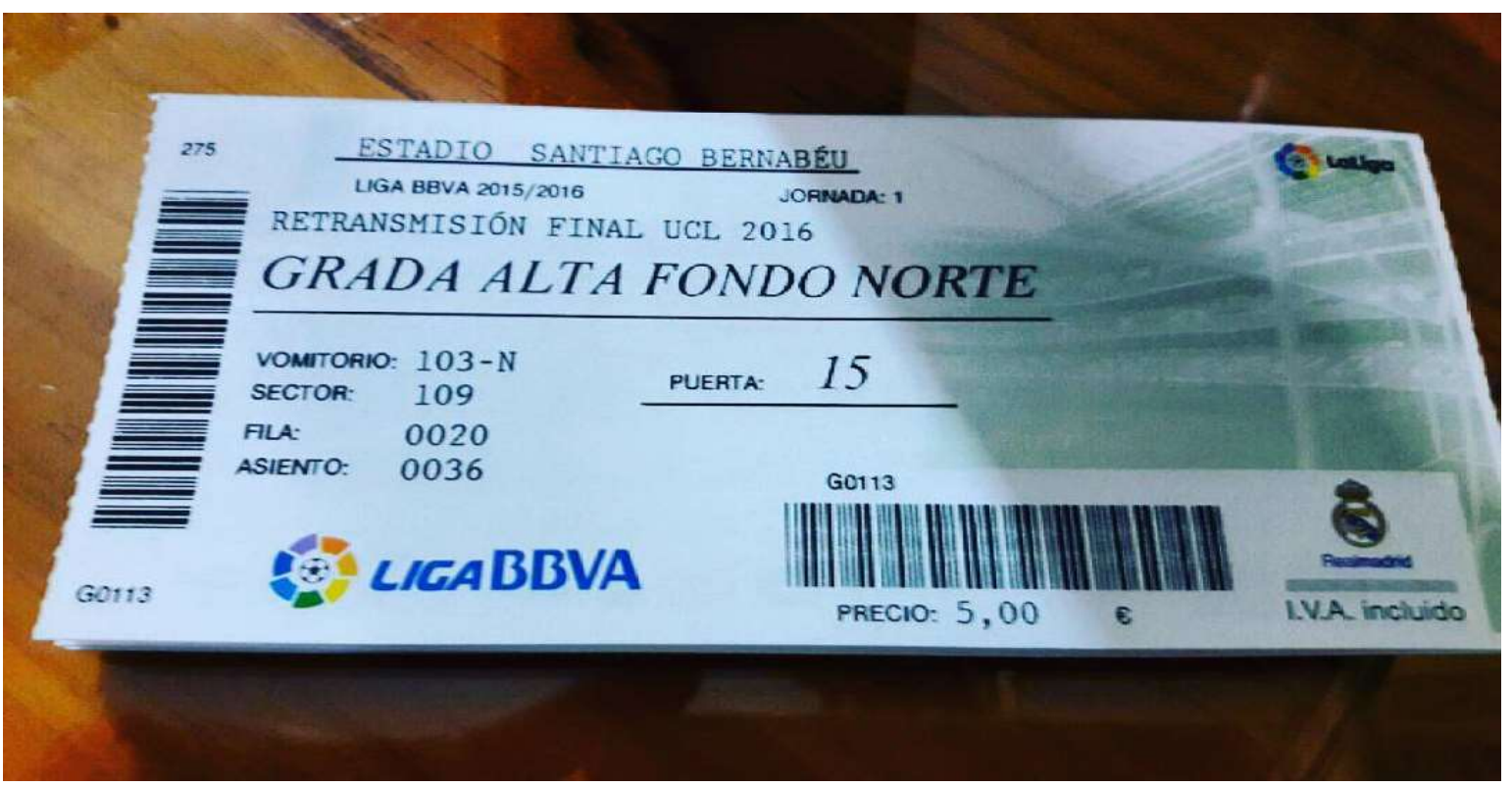

Figura 1 - Imagens por estádio

Fonte: Instagram - Mosaicos das fotos coletadas disponíveis em: http://www.coletachampions2016.tk.

Além disso, a equipe ao sagrar-se campeã retornou para a cidade onde foi recebida em seu estádio por mais de 30 mil torcedores no dia posterior a conquista ${ }^{8}$.

$\mathrm{Na}$ análise das postagens diárias (gráfico 2), o dia do jogo, como era previsto, foi o momento que obteve o pico de postagens. Essa constatação retrata o alto índice de mobilização para ações nas redes sociais no dia da partida, assim como a redução das postagens de acordo com o afastamento da data de realização do evento.

7 ABC.es. Disponível em: http://www.abc.es/espana/20140707/abci-equipos-futbol-preferidos-201407071256.html. Acesso em: 25 jun. 2016

8 Folha de São Paulo. Disponível em: http://www1.folha.uol.com.br/esporte/2016/05/ 1776117-apos-titulo-real-madrid-e-recebido-por-30-mil-torcedores-na-espanha.shtml. Acesso em: 25 jun. 2016. 


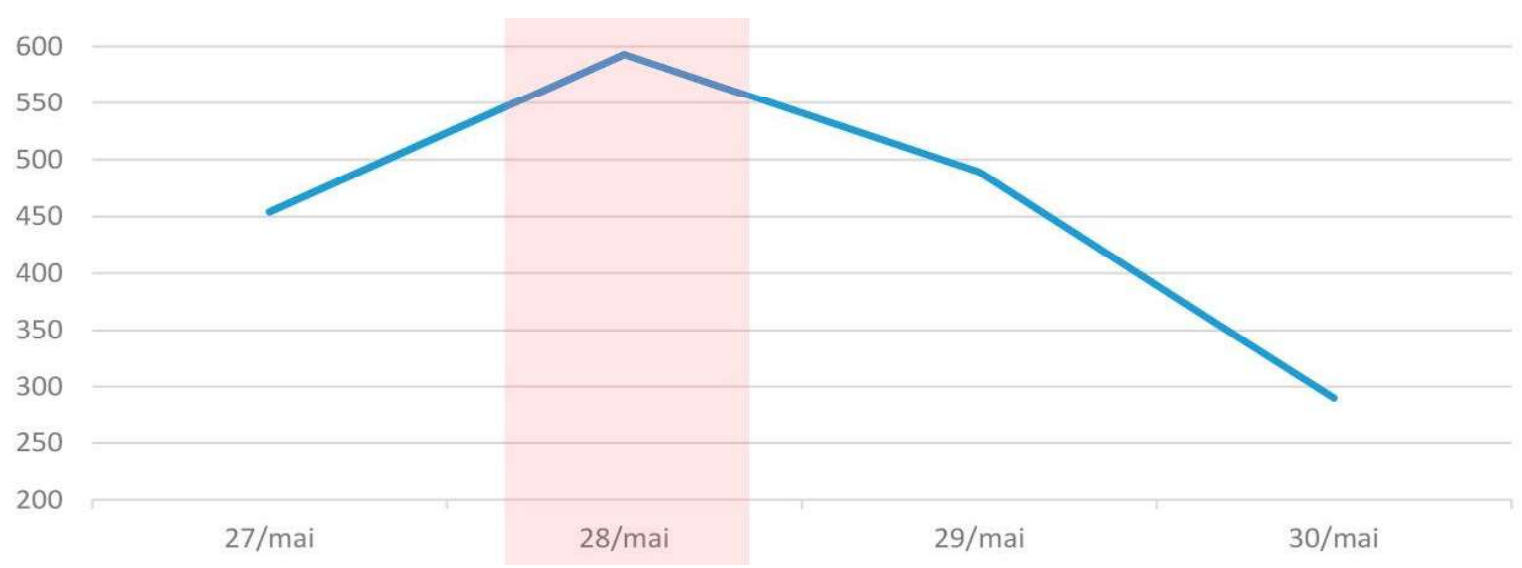

Gráfico 2 - Total de imagens postadas por dia

Fonte: Elaborado pelos Autores/ Dados completos coletados disponíveis em: http://www. coletachampions2016.tk.

É possível observar a variação de publicações por dia em cada local de acordo com o gráfico 3 . O pico de postagens foi identificado no dia do evento (28 de maio) e o estádio Santiago Bernabéu apresentou o maior índice.

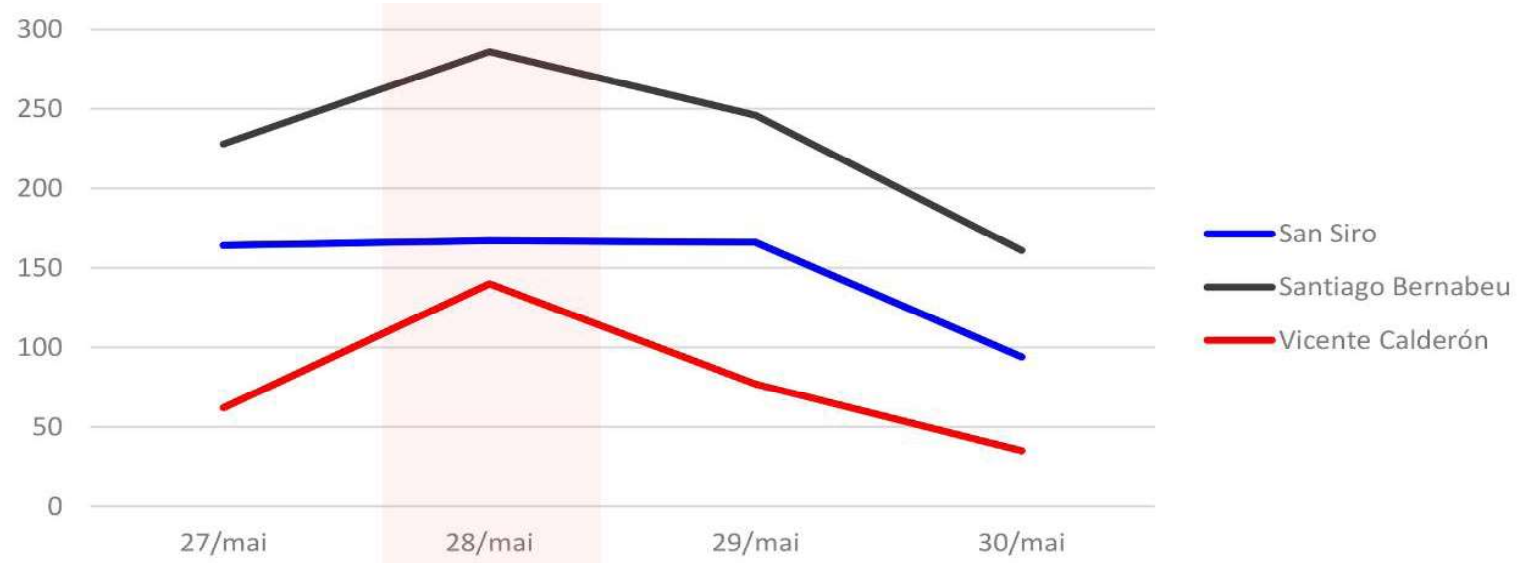

Gráfico 3 - Imagens postadas por dia e estádio

Fonte: Elaborado pelos Autores/ Dados completos coletados disponíveis em: http://www. coletachampions2016.tk.

O dia da partida (28 de maio) representou $29,7 \%$ do total das publicações, porém, o horário de realização do jogo (entre 20h e 24h) representou apenas $4,8 \%$. Os picos de publicações no dia da partida, de acordo com o gráfico 4 , aconteceram pela manhã (entre às $8 \mathrm{~h}$ e $9 \mathrm{~h}$ ) e nas 2 horas anteriores ao jogo. É difícil prever um motivo para o alto índice de postagens matinais, mas é possível inferir que ele ocorreu devido a um provável deslocamento dos torcedores para a cidade no mesmo dia 
do jogo, o que pode indicar uma postagem de "chegada", ou também um possível rito de "início das preparações" que abrange o clima envolto no dia do jogo. Já o pico ao final da partida pode ser considerado natural, tendo em vista que com a consagração do campeão a tendência é de um aumento significativo na frequência de postagens e comentários acerca do resultado obtido.

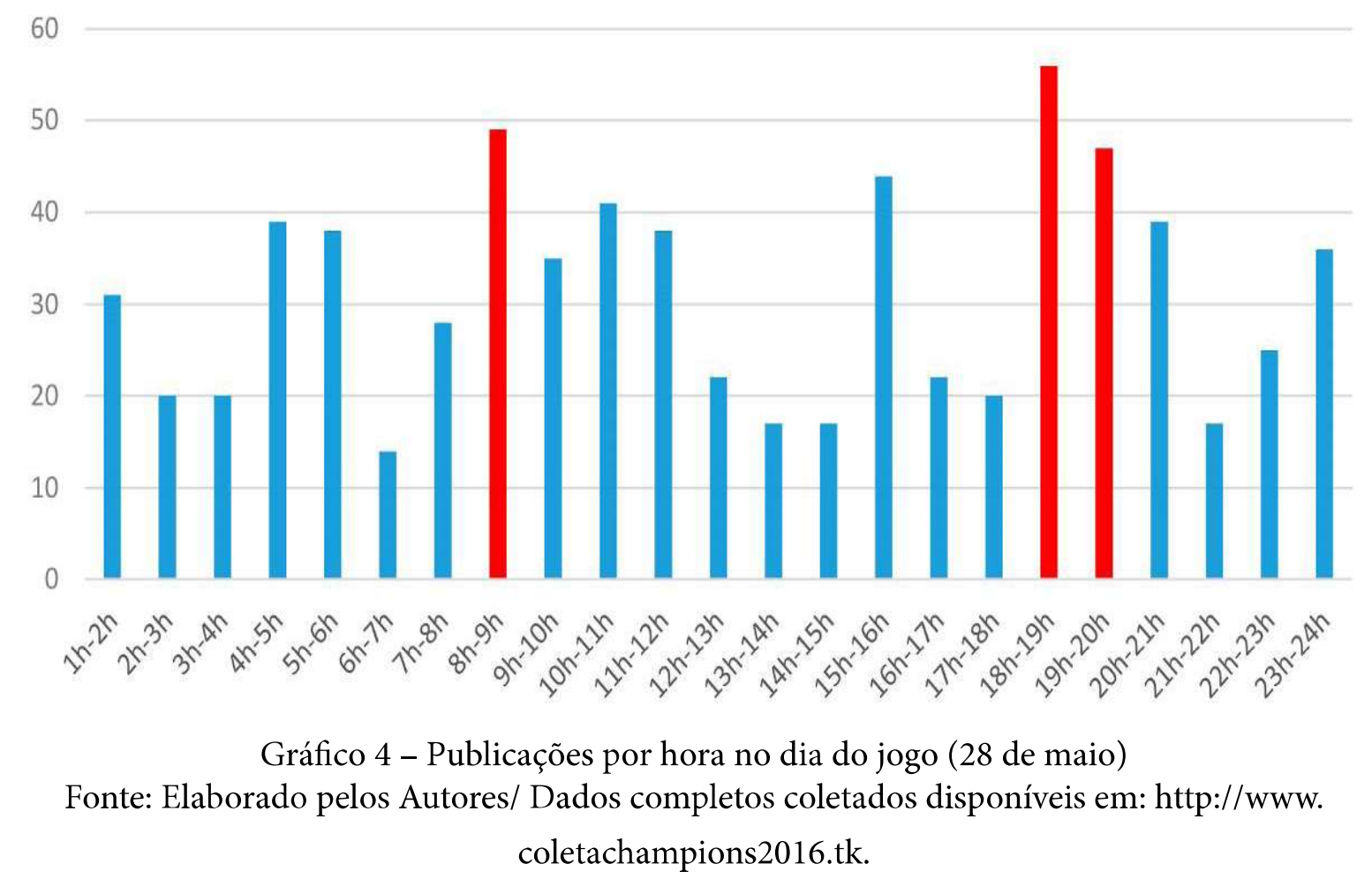

Para analisar a representatividade das fotos foi utilizado como base o projeto Selfiecity ${ }^{9}$, no qual Manovich (2014) ressalta a oportunidade aberta pelo Instagram para a realização de um estudo sobre a "cultura visual digital" na busca de relações e variações entre diferentes cidades. Nesse projeto, o autor analisou milhares de selfies postadas por usuários de diferentes cidades do mundo utilizando um software de reconhecimento de imagem e gerando mais de 20 categorias de análises. Baseado em Manovich (2014), as fotos coletadas foram analisadas a partir da ferramenta de reconhecimento de imagem presente no Google Photos ${ }^{10}$, em que, juntamente com uma filtragem manual, foi possível identificar um padrão interessante presente nas imagens. Esse padrão mostrava que era possível dividir as fotos em quatro grandes categorias relacionando-as

9 Selfiecity. Disponível em: http://selfiecity.net. Acesso em: 25 jun. 2016

10 Google Photos. Disponível em: https://photos.google.com. Acesso em: 25 jun. 2016. 
com a quantidade de pessoas retratadas nas imagens: nenhuma pessoa, apenas uma pessoa (muito provavelmente o autor do perfil coletado), duas pessoas e grupos com mais de duas pessoas, como apresenta o gráfico 5.

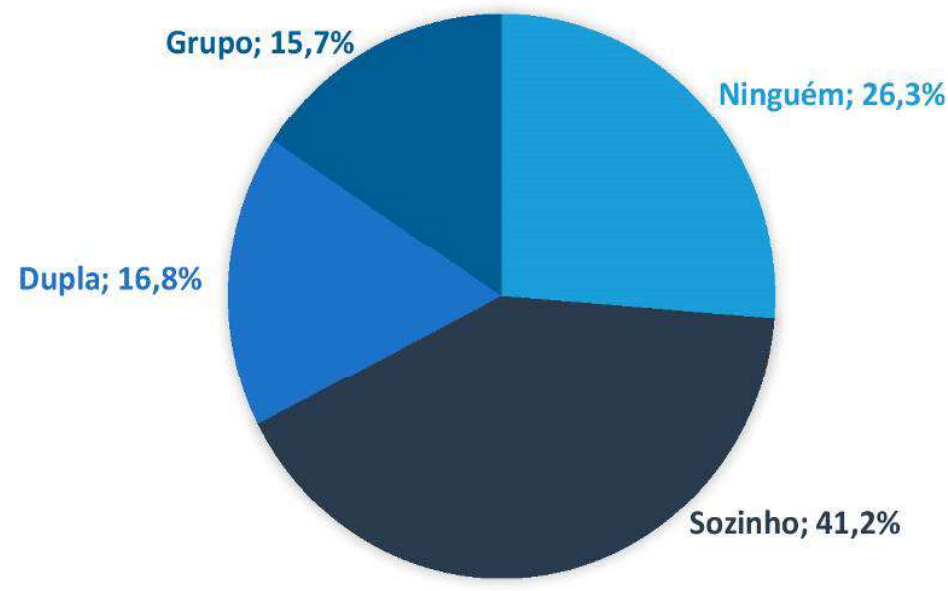

Gráfico 5 - Pessoas por foto - Geral

Fonte: Elaborado pelos Autores/ Mosaicos das fotos coletadas disponíveis em: http://www. coletachampions2016.tk.

A maioria das pessoas $(41,2 \%)$ publicaram fotos sozinhas, seguido por fotos sem nenhuma pessoa em primeiro plano $(26,3 \%)$. O somatório de fotos de pessoas sozinhas ou sem pessoas foi equivalente a $67,5 \%$ do total das imagens que representa mais de $2 / 3$ da coleta, enquanto duplas e grupos representam menos de $1 / 3$ das fotos $(32,5 \%)$.

Ao unificar essas categorias em dois grandes grupos: a) fotos com uma ou nenhuma pessoa e b) fotos com mais de uma pessoa, foi possível observar, independentemente do local, que a maioria das fotos postadas no Instagram retrataram uma ou nenhuma pessoa, variando de acordo com o local marcado.

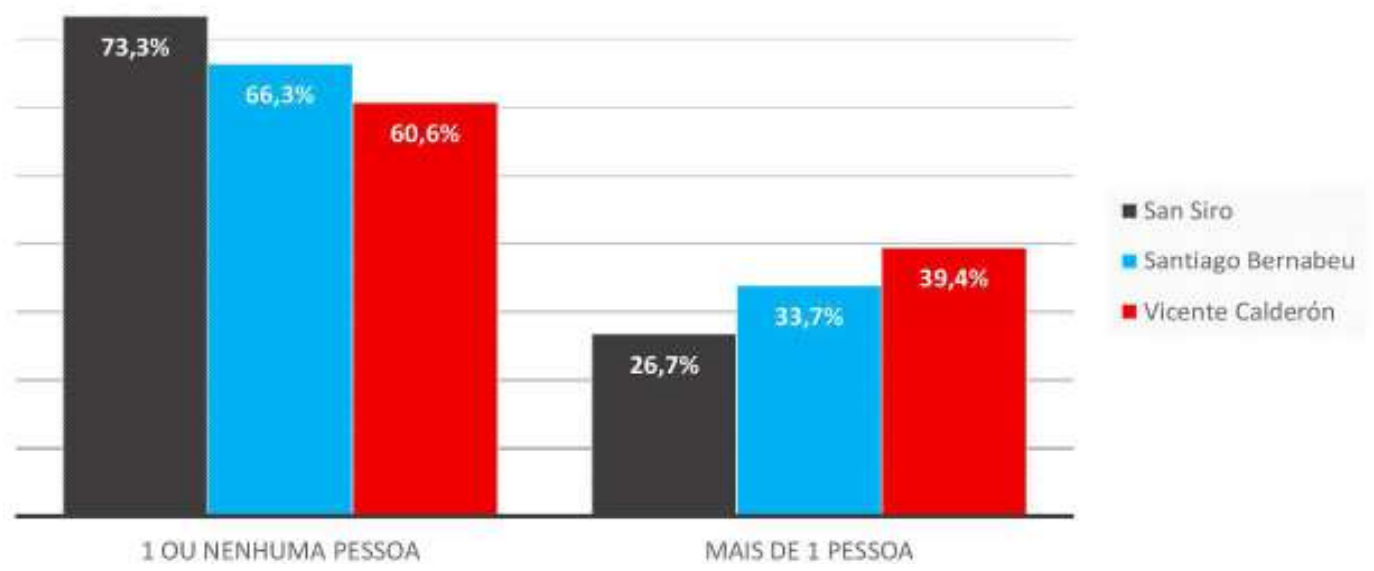


Gráfico 6 - Fotos por quantidade de pessoas agrupadas e por estádio Fonte: Elaborado pelos Autores/ Mosaicos das fotos coletadas disponíveis em: http://www. coletachampions2016.tk

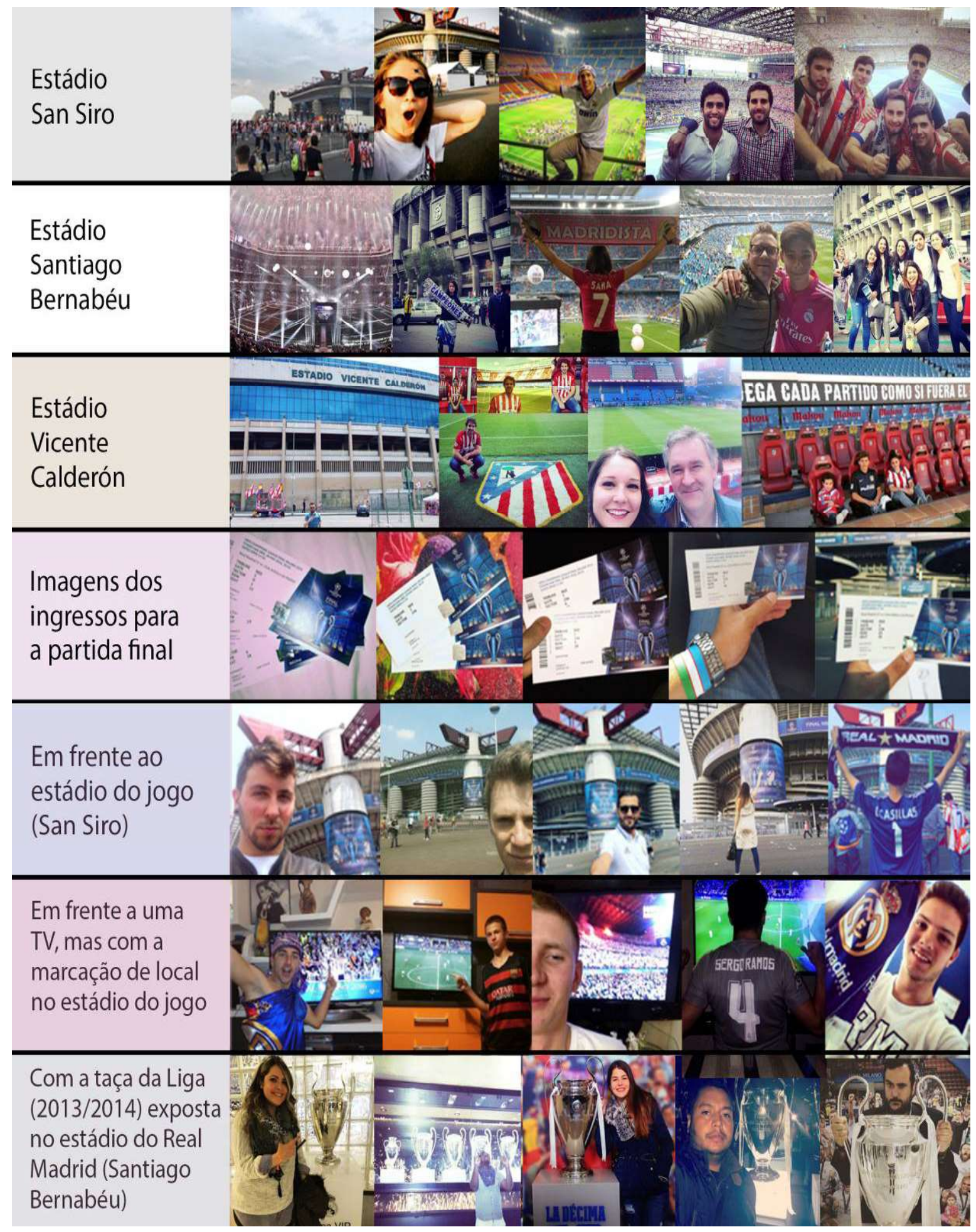

Figura 2 - Mosaico de algumas fotos coletadas Fonte: Elaborado pelos Autores a partir do Instagram/ Mosaicos das fotos coletadas disponíveis em: http://www.coletachampions2016.tk 
Além da análise quantitativa das imagens, foram elaborados mosaicos de todas as fotos coletadas segmentados por local e por categorias ${ }^{11}$, possibilitando uma visualização ampla e qualitativa das fotos e suas representatividades. A figura 2 apresenta um mosaico com algumas das imagens coletadas que permite identificar alguns dos padrões recorrentes.

\section{Considerações finais}

Com a análise das fotos e a estruturação dos dados apresentados foi possível estabelecer algumas conclusões. Os estádios de futebol são espaços com constante circulação de torcedores, esteja ocorrendo ou não uma partida ali. Obviamente, o movimento de pessoas no entorno do local tende a ser mais intenso quando está acontecendo alguma competição ou evento. Apesar de ser considerado um dos maiores eventos esportivos do mundo, a final da Liga dos Campeões e a localidade onde aconteceu o jogo (no caso, o campo neutro na Itália), não apresentou o maior índice de postagens. Mas o envolvimento das torcidas em seu local de origem acabou apresentando resultados mais intensos. Assim, é possível afirmar que não existem vínculos absolutos entre o local físico da partida e a frequência de postagens, uma vez que o espaço onde ocorre o evento não é necessariamente onde as postagens são mais frequentes. Esse é um dado que aponta para a ampla cobertura que o evento esportivo recebe, em especial uma final de campeonato internacional.

Cabe destacar que o jogo final foi transmitido para mais de 220 países e teve uma audiência estimada em mais de 180 milhões de pessoas ${ }^{12}$, o que igualmente contribuiu para tal comportamento. Do mesmo modo, o torcedor busca manifestar-se não importa onde esteja, demonstrando um pertencimento ao clube e ao evento, estabelecendo assim algum vínculo evidente, seja com a camiseta do clube, mostrando o local na imagem ou por meio de uma marcação no local da partida mesmo não estando fisicamente presente. Isso fica evidente nas repetições de comportamentos perante a câmera da figura 2 .

A mobilização social representada pela quantidade de postagens

11 Disponível em: <http://www.coletachampions2016.tk>.

12 UEFA.org. Disponível em: http://www.uefa.org/mediaservices/newsid=2357630.html. Acessado em: 30 de junho de 2016. 
está diretamente relacionada ao momento do evento, evidenciada a partir da identificação de que o dia da partida obteve maior frequência de interações. Por meio dos horários de pico das postagens foi possível identificar uma cronologia das atividades dos usuários, em que na manhã do dia do jogo (entre $8 \mathrm{~h}$ e $9 \mathrm{~h}$ ) está concentrada um número relevante de postagens. Esse período pode ser definido como as "postagens de abertura" do evento. As duas horas anteriores a partida foram as mais intensas, sendo então consideradas as "publicações pré-jogo". A queda drástica de postagens no decorrer da partida indica que o público tende a focar sua atenção estritamente à competição, deixando as redes sociais e registro de imagens de lado para assistir o evento.

A representação individualizada foi um fator evidente a partir dos dados analisados. A comunicação em mobilidade demonstra o que Pellanda (2009) chama de "hiperpessoal", termo utilizado pelo autor para designar os aparelhos que, diferente dos computadores pessoais, são utilizados estritamente por uma pessoa só. As fotos publicadas chamaram a atenção por, em sua maioria, serem representações de uma única pessoa e sua presença física no espaço. Isso pode ser observado com o registro da imagem de duas maneiras: a) pela apresentação do usuário na foto (imagens com uma única pessoa), e b) pelas fotos que mostram o ponto de vista do usuário (imagens sem nenhuma pessoa), representando o que a pessoa está vendo e onde está presente naquele momento.

Esse fenômeno fica claro a partir do momento em que é analisado o local de representação: o estádio de futebol. Esse espaço caracterizado pela presença de grandes públicos é comumente considerado um ponto de concentração física e aglomeração massiva de pessoas. Contudo, os usuários nesses espaços fizeram poucos registros em grupos, revelando uma relação paradoxal entre o modo de representação e o espaço físico em si. Apesar de estar em um ambiente com uma alta aglomeração de pessoas, o que é mostrado, na maior parte das vezes, é a "presença do eu" - por meio da autorrepresentação, ou da representação visual do próprio ponto de vista (imagem sem nenhuma pessoa).

Outro ponto a ser considerado é que o espaço físico do estádio, mesmo sem receber um evento, serve como representação de pertencimento da torcida. Não foram poucas as postagens geolocalizadas em estádios com fotos tiradas em ambientes distintos dos locais de marcação.

Os avanços tecnológicos da comunicação móvel e conectada per- 
mitem que as pessoas registrem e compartilhem momentos em tempo real. É possível considerar natural a publicação de uma foto em um determinado local no exato momento em que o usuário está presente. Entretanto, os locais físicos estão sendo transcendidos, viabilizando a demonstração de pertencimento, e até mesmo presença, mesmo estando a milhares de quilômetros de distância, simplesmente com uma demarcação virtual de localização.

A grande questão é que a tecnologia, ao mesmo tempo que permitiu a conexão e aproximação das pessoas deixando-as "a um clique de distância", trouxe também uma tendência de "hiperpessoalidade virtual" talvez a maior parte das publicações nas redes sociais não possuam uma representação coletiva, mas sim uma autorrepresentação. Ao analisar um evento massivo de uma final futebolística identificou-se uma possível tendência: as pessoas vivem em grupos e a tecnologia permite uma conexão constante. Todavia, a representação mais utilizada no ambiente virtual (plataformas digitais de redes sociais) muitas vezes é altamente pessoalizada, enfoca em um único indivíduo. A alta capacidade de conexão se dá principalmente pela proliferação e evolução tecnológica dos smartphones. Contudo, apesar de todos os avanços tecnológicos permitirem um constante e alto nível de conectividade, o fato de os aparelhos celulares serem cada vez mais utilizados de forma pessoal poderia resultar em um esvaziamento da representação coletiva do usuário, algo a ser investigado no futuro.

\section{Referências de apoio à pesquisa}

Este artigo reflete investigações desenvolvidas no laboratório interdisciplinar DaVint ${ }^{13}$ - Data Visualization and Interaction Lab, parcialmente financiado pelo Edital BPA/PUCRS/2017 No 05/2017 (Praias) e com o apoio do Edital Universal 2016-5 do CNPq. O presente trabalho foi realizado com apoio da Coordenação de Aperfeiçoamento de Pessoal de Nível Superior - Brasil (CAPES) - Código de Financiamento 001

13 Mais informações sobre o laboratório estão disponíveis em <http://www.inf.pucrs.br/davint>, consultado online em 10/04/2018. 


\section{REFERÊNCIAS}

CAIRO, Alberto. The functional art: an introduction do information graphics and visualization. Berkeley: New Riders, 2013.

HEER, J.; BOSTOCK, M.; OGIEVETSKY, V. A tour through the visualization zoo. Communications of the ACM, v.53, n.6, 2010, p. 59-67.

IBGE. Pesquisa Nacional por Amostra de Domicílios (Pnad, 2015). Disponível em: <http://biblioteca.ibge.gov.br/visualizacao/livros/liv95753. pdf >. Acesso em: 19 abr. 2014.

JENKINS, Henry. Cultura da Convergência. São Paulo: Aleph, 2009.

LEMOS, André; NOVAS, Lorena. Cibercultura e tsunamis: tecnologias de comunicação móvel, blogs e mobilização social. Revista da FAMECOS, Porto Alegre: EDIPUCRS, n.26, 2005.

LÉVY, Pierre. A inteligência coletiva por uma antropologia do ciberespaço. São Paulo, Loyola, 1995.

MANOVICH, Lev. Selfiecity: Exploring Photography and Self-Fashioning in Social Media, 2014. Disponível em: http://manovich.net/index. php/projects/selfiecity-exploring.

MEYROWITZ, Joshua. Global nomads in the digital veldt. In: Nyíri (ed.). Mobile democracy. Essays on Society, Self and Politics, Vienna: Passagen Verlag, p. 91-102, 2003.

MEYROWITZ, Joshua. No sense of place. New York: Oxford University Press, 1985.

MITTCHELL, William J. E-Topia: a vida urbana - mas não como a conhecemos. São Paulo: SENAC, 2002.

NEGROPONTE, Nicholas. Vida Digital. São Paulo, SP: Companhia das Letras, 1995. 
PELLANDA, Eduardo Campos. Comunicação Móvel no Contexto Brasileiro. In: LEMOS, Andre; JOSGRILBERG, Fabio (orgs.). Comunicação e Mobilidade: aspectos socioculturais das tecnologias móveis de comunicação no Brasil. Salvador, EDUFBA, 2009.

RECUERO, R. Análises de redes para mídias sociais. Porto Alegre: Sulina, 2015.

. Redes Sociais na Internet. Porto Alegre: Sulina, 2009.

RHEINGOLD, Howard. Smart Mobs. Cambridge: Perseus Publishing, 2003.

SANCHO, José Luis Valero. La infografía: técnicas, análisis y usos periodísticos. Bellaterra: UAB, 2001.

SANTAELLA, L. Linguagens líquidas na era da mobilidade. São Paulo: $1^{\text {a }}$ Ed. Paulus, 2007.

SALAVERRÍA, Rámon. Convergencia de los médios. In: Revista Latinoamericana de Comunicación CHASQUI, n. 81, p. 32-39. Ecuador, 2003.

TITCOMB, James. Mobile web browsing overtakes desktop for the first time. Telegraph, 1 nov. 2016. Disponível em: <https://www.telegraph. co.uk/technology/2016/11/01/mobile-web-usage-overtakes-desktop-for-first-time >. Acesso em: 19 abr. 2017.

TURKLE, Sherry. Alone Together. Why We Expect More from Technology and Less from Each Other. New York: Basic Books, 2011.

UEFA. Regulations of the UEFA Champions League 2015-18 Cycle. Disponível em: <https://pt.uefa.org/MultimediaFiles/Download/Regulations/uefaorg/Regulations/02/35/87/89/2358789_DOWNLOAD.pdf>. Acesso em: 19 abr. 2017.

YOUNG, Paul. The Nature of Information. Ann Arbor: Praeger Press, 1987, 192p. 
YUEXIAO, Zhang. Definitions and Sciences of Information. Information Processing \& 